\title{
Comportamiento y liderazgo político local en el Perú
}

\author{
Behaviour and local political leadership \\ in Perú
}

Comportamento e liderança política local no Perú

Edgar Quispe Mamani*

CONICET - Universidad Nacional de San Martín

Perú

\section{Resumen}

El artículo busca, por un lado, contribuir a la construcción de un marco de referencia para el estudio de los procesos y estilos del liderazgo político en los ámbitos locales, porque los enfoques analíticos que se conocen sobre el tema son bastante genéricos, ambiguos y limitados. Por otro lado, se pretende aplicar dicho marco de referencia al estudio del comportamiento y liderazgo político de los gobiernos locales en torno a los nuevos mecanismos de participación ciudadana implementados, durante las dos últimas décadas, en los ámbitos locales del Perú, y se formula un estilo de liderazgo político local desde la perspectiva de los actores.

Palabras claves: Política, liderazgo, participación, actores, alcaldes.

\begin{abstract}
This article is aimed, on the one hand, to contribute to the construction of a reference frame to study the political leadership processes and styles in local ambiences, because the analytical approaches known about the topic are quite general, ambiguous and limited. On the other hand, our aim is to apply the above mentioned reference frame onto behavior studies and political leadership of local governments
\end{abstract}

* Edgar Quispe Mamani: Ph. D. en Ciencia Política y Administración Pública, Universidad Autónoma de Madrid. Magíster en Sociología, Pontificia Universidad Católica del Perú. Director del Instituto Peruano de Investigación Quechua Aymara (JATHA-MUHU), Puno, Perú. Estancia de investigación y docencia posdoctoral en el Consejo Nacional de Investigaciones Científicas y Técnicas - CONICET, con centro de trabajo en la Escuela de Política y Gobierno de la Universidad Nacional de San Martín,Argentina.<edgar.quispe@pucp.edu.pe> 
concerning the new mechanisms of citizen participation implemented during the last two decades, in the local ambiences of Peru, thus formulating a style of local political leadership from the actors' point of view.

Keywords: Politics - Leadership - Participation - Actors - Mayors

\section{Resumo}

O artigo busca, por um lado, contribuir para a construção de um marco de referência para o estudo dos processos e estilos da liderança política nos âmbitos locais, porque os focos analíticos que são conhecidos sobre o tema, são bem genéricos, ambíguos e limitados. Por outro lado, procura-se aplicar dito marco de referência ao estudo do comportamento e liderança política dos governos locais em torno aos novos mecanismos de participação cidadã implementados durante as duas últimas décadas, nos âmbitos locais do Perú, e formula-se um estilo de liderança política local a partir da perspectiva dos atores.

Palavas-chave: Política - Liderança - Participação - Atores - Prefeitos

\section{Introducción}

El contenido de este artículo forma parte de los resultados de la investigación de tesis doctoral realizada por el autor en el periodo 2003-2007, la misma que lleva por título Gobiernos locales, participación ciudadana y liderazgo político local en el Perú y que fue defendida en abril de 2008 en la Universidad Autónoma de Madrid, cuya calificación fue "Sobresaliente cum laude" por unanimidad del tribunal. El objetivo del artículo es analizar, de manera comparada por regiones, el liderazgo político de los gobiernos locales en torno a los diferentes mecanismos de participación ciudadana en el marco de un sistema democrático representativo y de gobierno multinivel. Las regiones analizadas se distribuyen de la siguiente manera: Puno que está al sur, Ayacucho y Lima que se ubican al centro y Cajamarca en el norte del país. En cada una de estas regiones el estudio se realiza en sus capitales, considerando más de una o dos provincias importantes en términos de implementación del proceso participativo, salvo en el caso de Lima que se el distrito deVilla el Salvador. Los criterios de elección de estas cuatro regiones fueron fundamentalmente dos, por un lado, la implementación de las experiencias de participación con anterioridad y que han servido de referente a otras regiones $y$, por otro lado, la ubicación geográfica en las tres grandes regiones: sur, centro y norte, con el fin de que el análisis y los resultados alcanzados sean generalizables en el ámbito nacional.

Para fines del estudio se realizó un trabajo en gabinete, donde se prepararon los instrumentos de investigación: revisión de fuentes documentales relacionadas con nuestro 
tema de investigación, elaboración de guías de entrevista estructurada, la planificación del trabajo de campo y demás actividades. El trabajo de campo para la recopilación de información in situ se desarrolló en dos etapas. La primera etapa durante el otoño e inverno (de abril a agosto) de 2005.Y la segunda etapa en el invierno (de junio a agosto) de 2006. Durante estas dos etapas se hizo uso de tres técnicas y (o) instrumentos de investigación: primero, la revisión de fuentes secundarias, tales como estadísticas del Instituto Nacional de Estadística e Informática (INEI) y otros, archivos y documentos institucionales, publicaciones, etc. En segundo lugar, se aplicó una entrevista estructurada a los diferentes actores de manera diferenciada y de acuerdo al tipo de actores: municipales, estatales-regionales y sociedad civil local.Y, en tercer lugar, se realizó la observación participante de los distintos mecanismos o espacios de participación, en cada una de las regiones.

Ahora bien, debo explicitar que se hicieron, en general, 70 entrevistas en las cuatro regiones, cuyos resultados asumen una representatividad cualitativa y no así una evidencia estadística o cuantitativa, en la medida que los/as entrevistados/as han sido seleccionados por su representatividad social y política y el rol que desempeñan en el proceso de implementación de los nuevos mecanismos o espacios de participación ciudadana en los ámbitos locales estudiados. Por lo tanto, dado que la entrevista es la base y fuente principal de información del estudio, complementado por otras dos técnicas de investigación, a lo largo del artículo se utilizan los resultados de dicha entrevista con fines ilustrativos de los diferentes aspectos y dimensiones de la investigación. Por ejemplo, como quiera que las guías de entrevista aplicadas fueron estructuradas a modo de cuestionario; entonces, los datos cualitativos resultantes de dichas entrevistas fueron cuantificadas y presentadas en cuadros estadísticos, los cuales nos han permitido ilustrar mejor los hechos y las relaciones entre las variables del estudio.'

\section{Aproximaciones teóricas en torno al liderazgo político}

\section{I. Liderazgo político}

Los estudios y enfoques desarrollados sobre el liderazgo son variados tanto desde la sociología de las organizaciones como desde la psicología social; sin embargo, para situar el marco de análisis en torno al "liderazgo político local" expondremos

I En otras palabras, asumiendo el planteamiento de King, Keohane y Verba, la investigación se ha desarrollado a partir de una complementariedad metodológica entre las perspectivas cualitativa y cuantitativa. Los citados autores, sostienen que la mayoría de las investigaciones no corresponde claramente a una u otra categoría (o perspectiva), y las mejores suelen combinar características de los dos tipos. Para entender un mundo social en cambio constante tenemos que barajar información que no es fácilmente cuantificable y también la que sí lo es. Además, todas las ciencias sociales necesitan comparar, lo cual supone que se evalúe qué fenómenos se parecen "más" o "menos" en cuestión de grado (o sea diferencias cuantitativas) o de tipo (diferencias cualitativas). King, G. et al. El diseño de la investigación social. La inferencia científica en los estudios cualitativos. Alianza Editorial, Madrid. 2000. 
brevemente sobre algunos enfoques clásicos desarrollados en torno a este tema. ${ }^{2}$ Así, se han elaborado tres enfoques teóricos para los estudios de liderazgo, a saber: la teoría de los rasgos personales, la teoría del comportamiento (o conducta) y la teoría situacional.

Dado que los primeros estudios sobre el liderazgo se han enfocado desde la idea del "gran hombre", esto dio lugar a la formulación de la teoría de los rasgos personales, según la cual los líderes nacen, no se hacen. Es decir, según esta teoría los rasgos de los líderes son innatos y genéticos. De este modo, los estudios basados en esta teoría han intentado identificar un grupo de características o rasgos individuales que distinguían a los líderes respecto de los seguidores, y a los líderes exitosos respecto de los líderes fracasados. Sin embargo, esta comparación de los líderes con otros líderes y seguidores por varios rasgos físicos, intelectuales, de personalidad y otros, a pesar de haber sido un enfoque popular en su momento, ha sido controvertido tanto para los investigadores como para sus practicantes.

Por su parte, los estudios basados en los patrones del comportamiento (o de la conducta) de los líderes se desarrollan a raíz de las incongruencias de los estudios basados en los rasgos personales de los líderes, dando lugar a la teoría del comportamiento, centrado en los estilos de los líderes con respecto a su interacción con los miembros del grupo o los seguidores. Muchos investigadores de esta escuela de pensamiento sugieren que hay un "estilo mejor" para el rendimiento de organizaciones y equipos. De esta manera, los teóricos del comportamiento afirman que hay dos dimensiones u orientaciones en los líderes, a saber: los orientados a las personas y los orientados al cumplimiento de las tareas. En el primer caso, el líder enfatiza en las relaciones interpersonales abiertas y amistosas con las personas o sus seguidores, con el fin de provocar una influencia en ellos para construir y mantener relaciones de cooperación, y con ello generar confianza y apoyo. Y, en el segundo caso, el líder enfatiza tener el trabajo hecho mediante la organización, planeación, delegación, toma de decisiones y la coordinación de funciones y tareas.

Desde otra perspectiva, durante muchos años numerosos investigadores sobre el tema han cuestionado la premisa de que un estilo particular de liderazgo es efectivo en todos los escenarios o situaciones. En este sentido, los teóricos situacionales sostienen que el liderazgo de éxito depende de la situación organizacional y el estilo. Entre las variables situacionales que se han venido incorporando se pueden destacar el sistema formal de autoridad en la organización, la cultura, la tecnología, las percepciones de los seguidores respecto del líder, el grado de participación en la toma de decisiones colectivas o el sistema de información y comunicación, entre otras. Por lo tanto, entendemos que la teoría situacional defiende la no generalización de diferentes situaciones y contextos en que se desarrolla un determinado tipo o estilo de liderazgo, con lo cual

2 Para mayor detalle sobre el tema véase Bass, B. M. Bass and Stodgill's Handbook of Leadership:Theory, Research and Managerial Applications, $3^{\text {a }}$ edición. Nueva York:The Free Press, 1990; y Pascual, R. Liderazgo y participación: mitos y realidades. Bilbao: Universidad de Deusto, 1987. 
pensamos que, por ejemplo, una determinada teoría en torno al estilo de liderazgo democrático participativo desarrollado en las democracias occidentales no siempre o no necesariamente debe o puede ajustarse exactamente a una experiencia de liderazgo democrático participativo desarrollado en una democracia latinoamericana, porque los contextos de análisis son absolutamente diferentes.

Finalmente, en un estudio reciente Natera (I997 y 200I) ha identificado otro enfoque teórico para el estudio del liderazgo, a saber "el enfoque del nuevo liderazgo", el cual posee una naturaleza eminentemente interdisciplinar al integrar enfoques y modelos de distinta procedencia. Los estudios basados en este enfoque suelen dar énfasis en la distinción entre el liderazgo en sí y la gestión (management).Así, para los teóricos del nuevo liderazgo, mientras la gestión se enfrenta a la complejidad buscando la consistencia y el orden, el liderazgo por el contrario encara el cambio mediante la implantación de una visión en la realidad organizativa. Por tanto, la esencia del liderazgo, a diferencia de la gestión, residiría en la capacidad del líder para definir, articular y comunicar eficazmente una visión en el seno de su organización, aunque esta pueda ser tan vaga como un sueño o tan precisa como un objetivo o una misión.

A partir de estos enfoques teóricos desarrollados por innumerables investigadores, es que, el fenómeno del liderazgo, dada su dimensión política subyacente, también ha sido abordado por estudiosos de la Ciencia Política desde mediados de los años 70 del siglo pasado. Muchos estudios del liderazgo político según Natera (200I) se han abordado tomando como referencia el planteamiento de Paige, quien sostiene que las diferentes formas que el liderazgo pueda presentar dependen de la recíproca interacción de cinco variables básicas: personalidad, roles, tareas, valores y entorno específico. Por lo tanto, algunas concepciones del liderazgo político que expondremos a continuación responden en cierta medida a las características que hemos mencionado aquí. Asimismo, a modo de diferenciación entre las concepciones de líder y liderazgo, haremos un esfuerzo de redefinición del concepto del liderazgo político.

\subsection{Diferenciación entre líder y liderazgo}

En principio consideramos que la mayoría de las concepciones en torno al liderazgo político se han desarrollado, tomando en cuenta ya sea una o más variables, con un enfoque sesgado en las acciones del líder individual, dando lugar con ello a una concepción mágica o independiente del líder, es decir, como si el líder ya fuera dado en condiciones para influir de tal modo en el comportamiento colectivo. En este sentido, Edinger citado por Getimis y Hlepas (2006) define al líder como la persona quien ejerce control sobre el comportamiento de otros tanto como para mover a ellos en la dirección deseada. De modo similar, Leach y Wilson citados expuestos por los mismos autores, definen como la habilidad para inspirar o persuadir a otros para seguir un curso de acción donde al menos hay una resistencia inicial. En esta misma orientación, Baumgartner mencionado por Natera (200I) precisa al líder en función de sus habilidades individuales y de la manipulación de símbolos. Así, existe una cantidad de definiciones significados que se han extendido ampliamente en la academia. Es 
más, en concepciones como las que hemos expuesto se han utilizado, en muchos casos, indistintamente y de manera confusa las concepciones de "líder" y "liderazgo". Sin embargo, aquí se distinguen y se entiende por líder, como un actor individual que proyecta su comportamiento o acción en relación con diferentes grupos y sectores sociales e institucionales, cumpliendo sus funciones de impulso político, comunicación política, agregación de demandas e intereses colectivos, y legitimación del sistema político.

Ahora bien, desde un enfoque más realista y compartiendo el planteamiento de Natera, entiendo que el "liderazgo político" es un proceso relacional e interdependiente que surge de la interacción entre un actor individual y su ámbito de dominio político, entendido este como el espacio en que aquél aquel pretende tener un impacto, ya sea una institución, una política (policy), una localidad o un grupo de actores sociales o institucionales. Así como sostiene Natera, los procesos de liderazgo surgen y se consolidan no solo en función de las relaciones líderes-seguidores, sino también de las relaciones líderes-clientes, líderes-medios de comunicación, líderes-electores, etc., esto es, en función de sus relaciones con diferentes ámbitos de dominio político. De esta manera, el liderazgo político debe ser entendido como un proceso complejo (interacción) que incorpora tres componentes fundamentales: el comportamiento del líder individual (la interacción de su personalidad con el entorno), el ámbito de dominio político específico y la relación funcional entre ellos.

\subsection{Dimensiones del liderazgo político}

Como ya abordamos párrafos arriba, existen diferentes formas de enfocar el estudio de los procesos del liderazgo político, sin embargo, respondiendo a la concepción dada aquí exponemos sobre la dinámica de dos orientaciones o enfoques, en donde las dimensiones del proceso de liderazgo considerados tienen una complementariedad y que posteriormente darán lugar a la definición de los estilos del liderazgo político. El primer enfoque es el planteado por Natera (200I), quien identifica tres dimensiones en las que se desarrollan los procesos del liderazgo político: la adopción de decisiones políticas y la fijación de la agenda, la realización de tareas o trabajo político, y la búsqueda de recursos y apoyos.

Para el proceso de toma de decisiones y la definición de la agenda se plantean dos mecanismos: uno, que las decisiones son planificadas o programadas, este tipo de decisiones son rutinarias porque responden a un procedimiento regular para abordar la solución de problemas; mientras que, en segundo lugar, existen decisiones no programadas o imprevistas, este tipo de decisiones son novedosas y no existe un procedimiento para afrontar la solución de problemas. En la medida que las decisiones imprevistas no cuentan con un procedimiento, es donde el riesgo y la incertidumbre es mayor, por tanto, aquí es donde el liderazgo constituye un factor de enorme relevancia.

Por otra parte, el proceso de toma de decisiones conlleva consigo la influencia o no de los diferentes actores de acuerdo al ámbito de dominio político en el que actúa el líder. De modo que los estilos decisorios de los líderes políticos variarían desde las decisiones individualistas-autoritarios, pasando por las decisiones consultadas y las 
democráticas-participativas, para concluir con las decisiones delegadas y las decisiones de laissez-faire, es decir, cuando el líder político adopta las decisiones tomadas por otros sin su influencia. Este último estilo de decisión es muy poco común o con poca práctica. Pues bien, cada uno de estos estilos decisorios se utilizan de manera complementaria en determinadas situaciones y de acuerdo al dominio político en que actúa el líder. Sin embargo, habrá un estilo decisorio que habitualmente y en mayor medida sea utilizado por un determinado líder político, lo que ayudará a definir o tipificar su estilo de liderazgo.

Además, el proceso decisorio tiene dos orientaciones clásicas que responde a su carácter planificado y no planificado. Es decir, en la medida que las decisiones son planificadas la previsión o la anticipación a la solución de problemas es mayor en el tiempo, pudiendo ser la proyección para el mediano y largo plazo. Todo este proceso de planificación para la toma de decisiones se daría como resultado de la aplicación del modelo de "planificación racional-estratégica". De acuerdo a este modelo de toma de decisiones el líder tendría un amplio dominio sobre la situación y los problemas, ya que contaría con información y recursos suficientes. No obstante, las decisiones de carácter no planificado responden a la solución de problemas y situaciones críticas imprevistas, no porque no sean importantes, sino porque son apremiantes en el momento. Esto quiere decir que, a la par que discurre el tiempo, sobre la marcha se va fijando y redefiniendo la agenda política del líder.A este procedimiento es al que Lindblom denomina el modelo de la "racionalidad incremental" en el proceso de toma de decisiones, y según Natera modelo incremental-reactivo.

En segundo lugar, en cuanto al trabajo político de los líderes, es importante tomar en cuenta aquí las actividades y las tareas específicas en que ellos concentran en mayor medida su tiempo. Es decir, en la medida que la actividad de los líderes se concentra en un área temática específica o eje estratégico se podrá tipificar el rol fundamental que desempeñan. En este sentido, Natera (1997) ha clasificado a los líderes de acuerdo a sus roles percibidos en ellos, en las siguientes categorías: gestor/gerente, buscador de apoyos, impulsor político, jefe de la administración, impulsor de proyectos económicos, buscador de recursos, mediador entre intereses, buscador de mayor poder, representante de determinados sectores o intereses económicos, y negociador.

En tercer lugar, el proceso de liderazgo político se desarrolla en la búsqueda de recursos y apoyos, ya sean estos de carácter tangible o intangible. En el fondo lo que el líder pretende es construir una red de relaciones de diverso tipo, con personas, organizaciones e instituciones en los diferentes niveles (local, regional, nacional e internacional), con el fin de tomar decisiones para elaborar su agenda política y ponerlas en práctica. Esta red de relaciones alrededor del líder será construida tomando en cuenta una variedad de tipos de relaciones, entre ellas podemos destacar las relaciones de autoridad formal coercitivas o no, relaciones utilitarias simétricas, relaciones clientelares simétricas y asimétricas, relaciones articuladas en torno al logro de un objetivo compartido, relaciones basadas en la cooptación política, relaciones sociales de tipo personal basado en parientes y amistades. Al final y al cabo, estas redes relacionales se constituirán en las capacidades sociopolíticas de las que se servirá el líder para desarrollar su estilo de liderazgo. 
El segundo enfoque en torno a las dimensiones del liderazgo es el planteado por Getimis y Hlepas (2006), quienes consideran dos dimensiones para la definición de los estilos del liderazgo político local: la predisposición de liderazgo y las actitudes hacia el ejercicio del poder.

La primera dimensión da cuenta de la forma en que los líderes piensan desarrollar su rol. Así, el modo de desempeño de su rol puede desarrollarse de manera dicotómica bajo una orientación estratégica y otra orientación reproductiva. Entonces, dependiendo de cuál sea la predisposición de los alcaldes-líderes, estos pueden ser estratégicos en la medida que desarrollen agendas de política (policy) estratégica distintivas y que traten de incorporar en el proceso de policy-making de la autoridad, cuando piensen que la acción municipal es posible y deseable para orientar los desequilibrios económicos y sociales o para resolver los problemas sociales o económicos, y cuando establezcan objetivos de largo plazo para su entorno tratando de movilizar apoyos y esfuerzos para lograrlos. En otra orientación, los alcaldes-líderes también pueden ser reproductivos cuando ellos no desarrollan una agenda política (policy) de largo plazo y prefieren un esquema o estructura que deje más espacio para la reproducción del statu quo. Estos líderes orientados por la reproducción del statu quo se desarrollan por las siguientes razones: no tienen iniciativas, visiones ni dirección estratégica; creen que los procesos político y administrativo tomarían su curso natural prediseñado; no creen en la capacidad del gobierno local para promover transformaciones del contexto local; $y$ creen que los cambios y las soluciones a los problemas vienen del mercado y las políticas nacionales.

Por otra parte, la predisposición estratégica y reproductiva de los líderes también se puede distinguir mediante los siguientes criterios: el horizonte temporal del liderazgo y el alcance del líder. En el primer criterio se pueden distinguir dos categorías de liderazgo: proactivo y reactivo. Los alcaldes estratégicos prefieren actuar proactivamente en una perspectiva de largo plazo, transformando las estructuras institucionales, estableciendo objetivos claros que introducen en el proceso de policymaking municipal, $y$ apoyando un programa coherente y una estrategia de largo alcance. Mientras que los alcaldes reproductivos prefieren un comportamiento reactivo orientado a las actividades cotidianas bajo la perspectiva del corto plazo, sus acciones responden simplemente a cambios emergentes, a veces sin precedentes, y no consideran la formulación de nuevas políticas. En cuanto al segundo criterio referido al alcance del líder, el alcalde estratégico actúa como “creador de capacidades” (capacity builder) en el sentido que despliega una actitud positiva hacia el cambio y el fomento de la innovación, tratando de movilizar y atraer recursos de diferentes actores y promoviendo nuevos proyectos en la comunidad. Mientras que el alcalde reproductivo actúa como "supervisor" y mayormente se concentra en la corrección de la rutina del trabajo y las actividades municipales tradicionales, manteniendo el statu quo.

En cuanto a la segunda dimensión referida a las actitudes del líder hacia el ejercicio del poder se pueden distinguir dos formas: el deseo de actuar autoritariamente y el deseo de actuar cooperativamente. Un alcalde cooperativo que genera apoyo de la comunidad juega un rol crucial en la movilización de la sociedad civil local 
mediante la consolidación de reglas de procedimiento existentes y el establecimiento de nuevas que habiliten a los diferentes actores para participar e interactuar en la vida pública local; además, la movilización se basa en las relaciones personales para conseguir la gestión municipal. Mientras que el alcalde autoritario se caracteriza por una estructura jerárquica de autoridad y control, donde el control y la posesión del poder da menos importancia a las instituciones de participación ciudadana y al establecimiento de las redes de relaciones entre la comunidad y la autoridad local.

Tal como proponen Getimis y Hlepas, para identificar el estilo de liderazgo de los alcaldes ediles se puede analizar, por un lado, el modo de ejercicio del poder, y por otro lado, el modo de coordinación de las acciones. De esta manera, un alcalde cooperativo tendería a determinar la agenda municipal multilateralmente, incluyendo a otros actores y utilizando un estilo abierto en el ejercicio del poder. Mientras que alcalde autoritario tendería a ejercer el poder para determinar de manera unilateral la agenda municipal. De manera similar, el modo de coordinación de las acciones políticas de los alcaldes-líderes se distingue de acuerdo a su actitud cooperativa o autoritaria. Mientras que los alcaldes cooperativos tenderían a coordinar las acciones políticas, utilizando el consenso y los instrumentos de negociación y la deliberación; sin embargo, los alcaldes autoritarios coordinarían las acciones políticas empleando la autoridad del alcalde y preferirían los instrumentos de mando y control.

Considerando las diferentes dimensiones del liderazgo político expuestas hasta aquí, a continuación realizaremos la redefinición y construcción de los estilos del liderazgo político local que servirán de marco para el análisis del liderazgo político de los alcaldes en torno a la promoción y gestión de los nuevos mecanismos de participación ciudadana (siendo este un ámbito de dominio político de los alcaldes-líderes) en Perú.

\subsection{Estilos del liderazgo político local}

En esta sección intentamos redefinir y construir una tipología de estilos del liderazgo político local, asumiendo una perspectiva complementaria entre las dimensiones del liderazgo de este expuestas en la sección anterior y partiendo siempre de la concepción de que su desarrollo es un proceso relacional e interdependiente entre el líder y su ámbito de dominio político. Sin embargo, esta tipología es una propuesta abierta y una aproximación a un enfoque integrador para el estudio de los estilos del liderazgo político local.

Por lo tanto, se entiende por estilo del liderazgo como un proceso sociopolítico relacional, continuo y complementario que los líderes políticos desarrollan de cara a sus ámbitos de dominio político. Este proceso está configurado y desarrollado por el modo como se toman las decisiones políticas, el rol y el comportamiento político que asumen los líderes, la dinámica en el ejercicio de autoridad y el poder, y el modo como construyen sus redes de apoyo.

En el cuadro I se y definen algunos rasgos de cada uno de los estilos del liderazgo propuesto a partir de cuatro dimensiones. Además de estas características, cada estilo del liderazgo político es posible que pueda asumir otras características, por tanto, la propuesta es flexible y está abierta a cualquier contribución. 


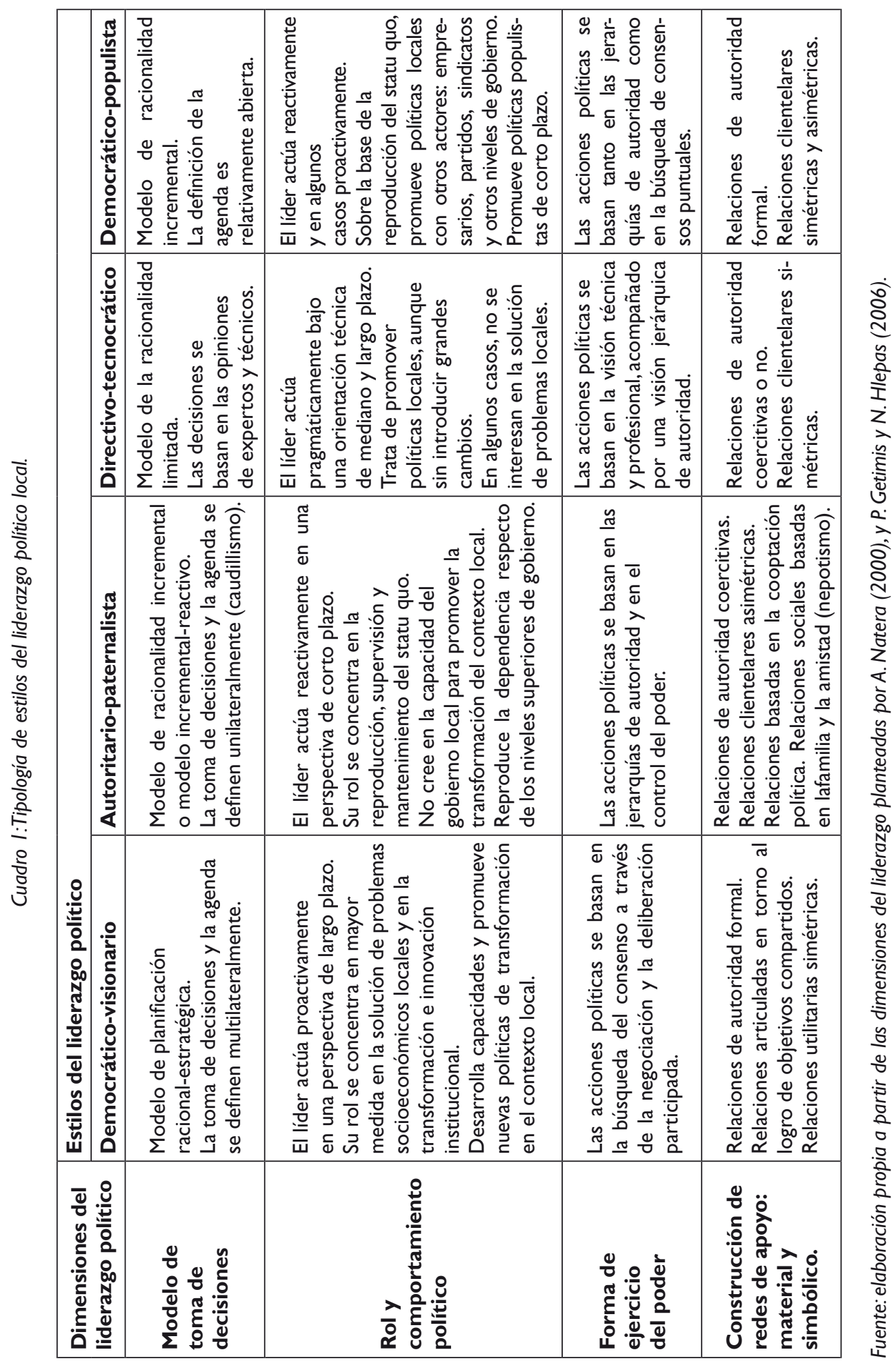




\section{Rol y comportamiento político de las autoridades locales: interacción con el entorno}

El proceso del liderazgo político desarrollado en las regiones estudiadas es diferenciado, puesto que el grado de proximidad y coordinación de las autoridades locales con los ciudadanos es diferente. Es decir, en la medida que se han implementado mecanismos de participación ciudadana para una mayor proximidad y mejor coordinación de las autoridades con la comunidad, la evaluación del comportamiento político de las autoridades locales por parte de la gente tiende a ser positiva. Este es el caso de los procesos de liderazgo en Villa el Salvador y Cajamarca, donde los alcaldes-líderes muestran una actitud relativamente proactiva y con una visión estratégica de mediano plazo; mientras que en Ayacucho y Puno, la evaluación del comportamiento político de las autoridades locales por parte de la ciudadanía tiende ha ser negativa, esto en la medida que los alcaldes-líderes actúan reactivamente, ${ }^{3}$ reproduciendo en cierta medida el statu quo. Estos líderes no cuentan con una visión ni dirección estratégica, sino por el contrario orientan sus acciones políticas de acuerdo a un estilo autoritario y populista.

Cuadro 2: Evaluación del comportamiento político de las autoridades locales por regiones estudiadas (en porcentajes).

\begin{tabular}{|l|r|r|r|r|r|}
\hline \multirow{2}{*}{$\begin{array}{c}\text { Evaluación de las } \\
\text { autoridades locales }\end{array}$} & \multicolumn{4}{|c|}{ Región } & \multirow{2}{*}{ Total } \\
\cline { 2 - 5 } & \multicolumn{1}{|c|}{ Puno } & Ayacucho & Cajamarca & Lima-VES & \\
\hline Buena & 0,0 & 12,5 & 0,0 & 25,0 & 9,4 \\
Regular & 40,0 & 25,0 & 50,0 & 50,0 & 40,6 \\
Mala & 60,0 & 62,5 & 50,0 & 25,0 & 50,0 \\
Total & 100,0 & 100,0 & 100,0 & 100,0 & 100,0 \\
\hline
\end{tabular}

Fuente: Elaboración propia a partir de los resultados de las entrevistas realizadas en las cuatro regiones estudiadas, 2005 y 2006.

Por otra parte, el comportamiento político de los alcaldes-líderes se complementa con el desempeño de diversas actividades políticas, ya sea en la búsqueda de apoyos y recursos, como jefe de la administración y negociador $y$, en algunos casos, como impulsor de proyectos de desarrollo socioeconómico. El desempeño de uno u otro rol por parte de los alcaldes-líderes responde, por un lado, al sistema político local que se reproduce del sistema político nacional (presidencialista) y a la estructura organizativa de los gobiernos locales que se encuentra definida en la Ley Orgánica de Municipalidades y, por otro lado, a la cultura política local. Estos dos factores hacen que la figura de los alcaldes-líderes

3 Los tipos de comportamiento político proactivo y reactivo de los alcaldes-líderes, planteados por Getimis y Hlepas (2006), responden a las acciones políticas cotidianas de las autoridades locales de cara a los ciudadanos y a través de los nuevos mecanismos participativos implementados en los ámbitos locales. Mecanismos de participación que son entendidos como ámbitos de dominio político para los alcaldes-líderes. 
estén cubiertas de diferentes roles, dando lugar a que la concentración de y funciones en estos actores sea ambigua entre lo político, lo administrativo y lo técnico.

La asignación de roles y funciones políticas, administrativas y técnicas al interior de los gobiernos locales estudiados es relativamente diferente. En la medida que el sistema de elección de las autoridades locales se basa en los principios de mayoría relativa, donde el movimiento o partido político ganador obtiene la mayoría de los concejales o regidores, entonces, estos últimos además de cumplir las funciones legislativa y fiscalizadora desde el concejo municipal, realizan o cumplen funciones actividades políticas y administrativas a través de las comisiones asignadas a cada uno/a. Estas comisiones giran en torno a ejes de trabajo de carácter sectorial, definidas en la estructura de organización municipal. Sin embargo, el desempeño de los regidores en cada una de las comisiones es prácticamente simbólico, porque, en primer lugar, las decisiones políticas son tomadas por el Concejo Municipal (presidido por el alcalde) $y$, en segundo lugar, las acciones administrativas y técnicas son ejecutadas por los funcionarios designados para dichas actividades. ${ }^{4}$ De esta manera, dado que la asignación de funciones roles en los gobiernos locales tanto en lo político y en lo administrativo como en lo técnico es ambigua, ${ }^{5}$ entonces la delegación de funciones y competencias municipales hacia los niveles inferiores están relacionadas relacionada con la implementación de las decisiones tomadas en las instancias superiores.

Por tanto, lo que podemos observar en el cuadro 3, se refiere a la delegación de funciones o competencias de carácter operativo o práctico. En este sentido, de acuerdo a nuestros entrevistados, en las cuatro regiones estudiadas las autoridades locales delegan funciones y competencias, en algunas regiones más que en otras, pero con una ligera diferencia. Podemos afirmar que el sistema político, la estructura organizativa municipal y la cultura política local, hacen que la asignación o redistribución de las funciones políticas, administrativas y técnicas, estén concentradas en mayor medida en el ápice estratégico, conformado por los políticos y técnicos. Aunque durante los últimos años este proceso convencional de gestión de los gobiernos locales ha sido permeabilizado por la emergencia de los nuevos mecanismos de participación ciudadana, haciendo que las decisiones del gobierno local tengan una mayor sensibilidad con el entorno social. En esta orientación Haus y Sweeting (2006), sostienen que la democracia local desde la perspectiva participa-

4 Este proceso es lo que hemos podido identificar y observar en la dinámica de funcionamiento y gestión de los gobiernos locales estudiados, todo ello se desprende tanto de la estructura organizativa y político-institucional como de la tradición y cultura política locales.

5 A este respecto,Alba y Navarro (2006), sostienen que el desempeño de las funciones y competencias de los líderes políticos electos por los ciudadanos y los funcionarios administrativos designados al interior de un gobierno local, depende del tipo de sistema en el que se enmarca el funcionamiento y la estructura de organización municipal. Para ellos, en la mayoría de los casos es que las funciones y competencias políticas y administrativas suelen estar definidas o separadas claramente, donde los políticos se encargan fundamentalmente de la definición de los objetivos políticos y los resultados de las acciones políticas; mientras que los funcionarios administrativos o burócratas se encargarían de la definición y diseño técnico de las políticas y programas de acción concretos. Sin embargo, dado que el sistema de gobierno local peruano es de alcalde fuerte, entonces la superposición de funciones y competencias al interior de los gobiernos locales es bastante marcada. 
tiva, implica la negociación y generación de consensos en la definición de la agenda política local entre los políticos locales, administrativos-funcionarios (burócratas) y ciudadanos. Así, la democracia se convierte en un sistema compuesto por las dimensiones política, administrativa y social.

Cuadro 3: Delegación de funciones y competencias de las autoridades locales por regiones estudiadas (en porcentajes).

\begin{tabular}{|l|r|r|r|r|r|}
\hline \multirow{2}{*}{$\begin{array}{c}\text { Delegación de funciones y } \\
\text { competencias }\end{array}$} & \multicolumn{4}{|c|}{ Región } & \multicolumn{1}{c|}{ Total } \\
\cline { 2 - 6 } & \multicolumn{1}{|c|}{ Puno } & Ayacucho & Cajamarca & Lima-VES & \\
\hline Sí, en gran medida & 44,4 & 50,0 & 70,0 & 41,7 & 52,9 \\
Sí, en cierta medida & 33,3 & 40,0 & 20,0 & 50,0 & 34,3 \\
No delega funciones & 22,2 & 10,0 & 10,0 & 8,3 & 12,9 \\
y competencias & 100,0 & 100,0 & 100,0 & 100,0 & 100,0 \\
Total & & & & \\
\hline
\end{tabular}

Fuente: Elaboración propia a partir de los resultados de las entrevistas realizadas en las cuatro regiones estudiadas, 2005 y 2006.

\section{Modelo implementado para la toma de decisiones}

El modelo de toma de decisiones a nivel político y técnico al interior de los gobiernos locales en Perú responde, nuevamente, al sistema político, la estructura organizativa a nivel municipal y la cultura política local. Es decir, en la medida que el sistema político presidencialista, la estructura de organización vertical y la cultura política local caudillista generan una concentración del poder de toma de decisiones en el alcalde y su entorno político, entonces, los mecanismos de toma de decisiones en los ámbitos locales son de carácter imprevisto o no planificado y responde a un horizonte temporal de corto plazo, es decir, estos mecanismos decisorios hacen que las decisiones se vayan tomando sobre la marcha en la construcción de la agenda política del líder. De modo que el estilo decisorio de los líderes políticos tiende a ser, en mayor medida, de carácter individualista-autoritario, aunque hay un proceso formal de decisiones participadas que se viene desarrollando tímidamente con la implementación de los nuevos mecanismos de participación ciudadana en el país.

El modelo convencional de toma de decisiones implementado en los gobiernos locales ha hecho que la frecuencia de comunicación de las autoridades locales con los ciudadanos sea, en general, considerablemente baja. Este panorama de interacción o comunicación entre autoridades y ciudadanos es más marcado en ámbitos locales donde los nuevos mecanismos de participación ciudadana fueron implementados por mimetismo, tales como en Ayacucho y en Puno (véase el cuadro 4); mientras que el panorama es relativamente diferente en Cajamarca y en Villa el Salvador, donde el proceso participativo emergente ha dado lugar a que haya un cambio relativo en el modelo de toma de decisiones. 
La baja frecuencia de comunicación entre autoridades y ciudadanos es percibida, de sobremanera, por los actores de la sociedad civil local, seguido de los actores estatales (véase el cuadro 5), cuyas percepciones dan cuenta de una baja y muy baja frecuencia de comunicación de las autoridades locales con los ciudadanos. Todo ello indica que el proceso de toma de decisiones en los gobiernos locales es cerrado y muy poco participativo, ${ }^{6}$ a pesar de que los actores municipales sostienen que aquella frecuencia de comunicación es relativamente alta.

Cuadro 4: Frecuencia de comunicación de las autoridades locales con los ciudadanos por regiones estudiadas (en porcentajes).

\begin{tabular}{|l|r|r|r|r|r|}
\hline \multirow{2}{*}{$\begin{array}{c}\text { Frecuencia de comunicación } \\
\text { con los ciudadanos }\end{array}$} & \multicolumn{4}{|c|}{ Región } & \multirow{2}{*}{ Total } \\
\cline { 2 - 5 } & \multicolumn{1}{|c|}{ Puno } & Ayacucho & Cajamarca & Lima-VES & \\
\hline A diario & 27,8 & 15,0 & 30,0 & 25,0 & 24,3 \\
2-4 veces por semana & 5,6 & 10,0 & 10,0 & 0,0 & 7,1 \\
Una vez por semana & 5,6 & 10,0 & 20,0 & 8,3 & 11,4 \\
I-3 veces al mes & 11,1 & 15,0 & 5,0 & 25,0 & 12,9 \\
Trimestralmente & 0,0 & 15,0 & 10,0 & 16,7 & 10,0 \\
Rara vez o nunca & 50,0 & 35,0 & 25,0 & 25,0 & 34,3 \\
Total & 100,0 & 100,0 & 100,0 & 100,0 & 100,0 \\
\hline
\end{tabular}

Fuente: Elaboración propia a partir de los resultados de las entrevistas realizadas en las cuatro regiones estudiadas, 2005 y 2006.

Cuadro 5: Frecuencia de comunicación de las autoridades locales con los ciudadanos por actores entrevistados (en porcentajes).

\begin{tabular}{|l|r|r|r|r|}
\hline \multirow{2}{*}{$\begin{array}{c}\text { Frecuencia de comunicación con } \\
\text { los ciudadanos }\end{array}$} & \multicolumn{2}{|c|}{ Tipo de actor entrevistado } & \multirow{2}{*}{ Total } \\
\cline { 2 - 4 } & Municipal & Estatal & \multicolumn{1}{c|}{ Soc. civil } & \\
\hline A diario & 45,0 & 25,0 & 10,0 & 24,3 \\
-2-4 veces por semana & 15,0 & 10,0 &, 0 & 7,1 \\
Una vez por semana & 10,0 & 15,0 & 10,0 & 11,4 \\
I-3 veces al mes & 25,0 & 10,0 & 6,7 & 12,9 \\
Trimestralmente & 5,0 & 10,0 & 13,3 & 10,0 \\
Rara vez o nunca & 0,0 & 30,0 & 60,0 & 34,3 \\
Total & 100,0 & 100,0 & 100,0 & 100,0 \\
\hline
\end{tabular}

Fuente: Elaboración propia a partir de los resultados de las entrevistas realizadas en las cuatro regiones estudiadas, 2005 y 2006.

6 Esta lógica en el estilo de toma de decisiones a nivel de los gobiernos locales estaría generando escenarios de desafección política de los ciudadanos y, es más, estaría generando insatisfacción y conflictos sociopolíticos, como el ocurrido en la provincial del Collao, llave en la región Puno: revuelta popular y asesinato del alcalde provincial en 2003. 
En relación con lo anterior, en la medida que el modelo convencional de toma de decisiones en los gobiernos locales es cerrado y poco participativo, entonces, la agenda de acciones municipales responde en menor medida a las demandas y necesidades sentidas de los ciudadanos, este es el caso de Ayacucho y Puno (véase el cuadro 6). Sin embargo, en la medida que el proceso de toma de decisiones en los gobiernos locales éstos es relativamente participativo, el grado de respuesta de la agenda municipal a las demandas y necesidades de los ciudadanos es relativamente alto, este es el caso de Cajamarca y Villa el Salvador, donde ellos tienen una mayor participación en el proceso de identificación de los problemas y con ello contribuyen en la definición de las políticas públicas locales. Todo ello hace que los líderes políticos desarrollen estilos decisorios de carácter democrático-participativo y consultado.

Cuadro 6: Respuesta de la agenda de acciones municipales a las demandas y necesidades ciudadanas por regiones estudiadas (en porcentajes).

\begin{tabular}{|l|r|r|r|r|r|}
\hline \multirow{2}{*}{$\begin{array}{c}\text { Respuesta de la agenda } \\
\text { municipal a la ciudadanía }\end{array}$} & \multicolumn{4}{|c|}{ Región } & \multirow{2}{*}{ Total } \\
\cline { 2 - 5 } & \multicolumn{1}{|c|}{ Puno } & Ayacucho & Cajamarca & Lima-VES & \\
\hline Si completamente & $1 \mathrm{I}, \mathrm{I}$ & 5,0 & 10,0 & 0,0 & 7,1 \\
\hline Si en gran medida & 5,6 & 35,0 & 45,0 & 41,7 & $3 \mathrm{I}, 4$ \\
\hline Si en cierta medida o poco & 50,0 & 55,0 & 35,0 & 50,0 & $47, \mathrm{I}$ \\
\hline No responde en nada & 33,3 & 5,0 & 10,0 & 8,3 & 14,3 \\
\hline Total & 100,0 & 100,0 & 100,0 & 100,0 & 100,0 \\
\hline
\end{tabular}

Fuente: Elaboración propia a partir de los resultados de las entrevistas realizadas en las cuatro regiones estudiadas, 2005 y 2006.

\section{Forma de ejercicio del poder por parte de los líderes políticos}

La forma de ejercicio del poder en los ámbitos locales en Perú está ligada directamente a la tradición y la cultura política locales. En este sentido, la experiencia de trabajo en estos ámbitos nos da cuenta que, de modo general, las autoridades locales (alcaldes) tipificados como líderes, ejercen su poder en función a de los rasgos autoritarios y caudillistas, propios de la época de las haciendas o del latifundismo, según los cuales la agenda de acciones municipales es definida unilateralmente. De esta manera, el modelo de ejercicio del poder por parte de aquellos líderes es cerrado, porque los diferentes sectores sociales e institucionales son excluidos del proceso de las políticas locales.

Según Vargas (2003), durante los años 90 han surgido una serie de líderes locales de nivel provincial, quienes más para reaccionar ante las políticas del Estado que con propuestas proactivas que reflejen autonomía y madurez ideológica y política. Estos líderes provinciales fueron caudillos, posiblemente sin tener plena conciencia de ello, porque a la hora de tomar decisiones importantes excluían de forma radical a los actores sociales que actuaban como soporte de sus gestiones, porque no estaban articulados de manera 
orgánica. Ejemplos de este tipo de ejercicio del poder, podemos mencionar a Federico Salas en Huancavelica, Gregorio Ticona en Puno yWaldo Ríos en Huaraz. Este modelo de ejercicio del poder está ligado a la tradición y la cultura política locales, porque sus acciones están basadas en la estructura jerárquica de autoridad, donde el control y la posesión del poder dan menos importancia al diálogo, la participación ciudadana y al establecimiento de las redes de relaciones entre la comunidad y la autoridad local.

Ahora bien, de acuerdo con nuestros entrevistados a nivel regional, la apertura a la información ciudadana y participación de los mismos en el proceso de gestión municipal es bastante limitada, porque la frecuencia de rendición de cuentas de las autoridades a los ciudadanos se realizan esporádicamente, aunque en Ayacucho y Cajamarca, la mayoría de nuestros entrevistados sostuvieron que este proceso fue como un mecanismo de participación ciudadana que se produce de manera relativamente permanente, corroborando este hecho, en Ayacucho es el único ámbito donde se ha observado una mayor apertura de las autoridades locales para brindar o proveer información a los ciudadanos a través de mecanismos participativos como las sesiones de consejo municipal, los cuales son abiertos a la comunidad en general, ${ }^{7}$ sobre esta base es que nuestros entrevistados habrían expresado que la rendición de cuentas y (o) provisión de información de las autoridades locales a los ciudadanos es más frecuente. En tanto que, en los demás ámbitos estudiados, a pesar de que el proceso participativo haya sido más dinámico, como en Villa el Salvador, sin embargo, los ciudadanos sostuvieron que el proceso de rendición de cuentas por parte de las autoridades municipales es muy esporádico (véase cuadros 7 y 8). Todo ello nos estaría indicando que el liderazgo en el proceso participativo tiene dos orientaciones: primero, es dónde y cuándo los alcaldes-líderes abren mecanismos de participación ciudadana para el proceso de identificación de problemas y definición de políticas locales (proceso de toma de decisiones), estos líderes ejercen el poder de acuerdo a los rasgos cooperativos, cuya coordinación de acciones políticas se basa en el consenso y los instrumentos de negociación y deliberación. En segundo lugar, es dónde y cuándo los alcaldes-líderes abren mecanismos de participación ciudadana, únicamente, para proveer información a los ciudadanos en cuanto a la gestión económica municipal, por lo general, anualmente, ${ }^{8}$ estos líderes ejercen el poder de acuerdo a los rasgos relativamente autoritarios y las coordinaciones para sus acciones políticas se basan en la autoridad del alcalde y prefieren hacer uso de los instrumentos de mando y control.

7 De acuerdo con la nueva Ley Orgánica de Municipalidades $n^{\circ}$ 27972, las sesiones del concejo municipal son abiertas al público, donde los ciudadanos tienen derecho a opinar y plantear propuestas de acción para solucionar los problemas sociales o de otra índole.

8 Con la apertura o ejecución de este tipo de mecanismos participativos, las autoridades locales estarían respondiendo o cumpliendo únicamente los procedimientos establecidos en la normativa vigente. Es decir, estos mecanismos participativos son de carácter meramente formal y de promoción/propaganda política de los líderes políticos, en algunos casos. 
Cuadro 7: Frecuencia de rendición de cuentas de las autoridades locales por regiones estudiadas (en porcentajes).

\begin{tabular}{|l|r|r|r|r|r|}
\hline \multirow{2}{*}{$\begin{array}{c}\text { Frecuencia de rendición } \\
\text { de cuentas }\end{array}$} & \multicolumn{4}{c|}{ Región } & \multirow{2}{*}{ Total } \\
\cline { 2 - 5 } & \multicolumn{1}{|c|}{ Puno } & Ayacucho & Cajamarca & Lima-VES & \\
\hline Mensualmente/trimestralmente & 16,7 & 45,0 & 45,0 & 8,3 & 31,4 \\
Semestralmente & 11,1 & 15,0 & 30,0 & 8,3 & 17,1 \\
Anualmente & 27,8 & 30,0 & 5,0 & 66,7 & 28,6 \\
Cada 2 años & 5,6 & 5,0 & 0,0 & 0,0 & 2,9 \\
Rara vez o nunca & 38,9 & 5,0 & 20,0 & 16,7 & 20,0 \\
Total & 100,0 & 100,0 & 100,0 & 100,0 & 100,0 \\
\hline
\end{tabular}

Fuente: Elaboración propia a partir de los resultados de las entrevistas realizadas en las cuatro regiones estudiadas, 2005 y 2006.

Cuadro 8: Frecuencia de rendición de cuentas de las autoridades locales por tipo de actor entrevistado (en porcentajes).

\begin{tabular}{|l|r|r|r|r|}
\hline \multirow{2}{*}{ Frecuencia de rendición de cuentas } & \multicolumn{2}{|c|}{ Tipo de actor entrevistado } & \multirow{2}{*}{ Total } \\
\cline { 2 - 4 } & Municipal & \multicolumn{1}{|c|}{ Estatal } & \multicolumn{1}{|c|}{ Soc. civil } & \\
\hline Mensualmente/trimestralmente & 45,0 & 60,0 & 3,3 & 31,4 \\
Semestralmente & 20,0 & 25,0 & 10,0 & 17,1 \\
Anualmente & 35,0 & 5,0 & 40,0 & 28,6 \\
Cada 2 años & 0,0 & 0,0 & 6,7 & 2,9 \\
Rara vez o nunca & 0,0 & 10,0 & 40,0 & 20,0 \\
Total & 100,0 & 100,0 & 100,0 & 100,0 \\
\hline
\end{tabular}

Fuente: Elaboración propia a partir de los resultados de las entrevistas realizadas en las cuatro regiones estudiadas, 2005 y 2006.

\section{Construcción de redes de apoyo}

En concordancia con lo que se ha expuesto en las secciones anteriores, la construcción de las redes de apoyo de los alcaldes-líderes está influida por la tradición política y la cultura política locales. Es decir, para la implementación de las políticas locales los líderes políticos recurren a redes de apoyo basados en las relaciones de autoridad formal (en muchas oportunidades de carácter autoritario y coercitivo), en las relaciones clientelares asimétricas y en las relaciones de tipo personal basado en parientes y amistades. De esta manera, hemos podido observar que los rasgos autoritarios y caudillistas de los líderes políticos locales están presentes en la forma de ejercicio del poder.Así, sus redes de relaciones políticas giran en torno al control del poder y mando, aunque en ámbitos locales como Villa el Salvador o Cajamarca, las redes de apoyo político para 
la implementación de algunas políticas se basan en las relaciones utilitarias simétricas entre los líderes políticos y la sociedad civil local, según la cual los resultados de dichas políticas benefician de manera relativamente igualitaria a los diferentes actores locales.

Por tanto, en la medida que las redes de relaciones políticas de los alcaldeslíderes están basadas mayoritariamente en el control del poder y mando, entonces el grado de coordinación y la apertura al diálogo entre las autoridades locales y demás actores concernidos en los ámbitos locales tiende a ser bajo. Esta tendencia es lo que podemos observar en el cuadro nueve, donde Ayacucho y Puno salen mal parados en comparación con los casos de Cajamarca y Villa el Salvador.

La tendencia al bajo grado de coordinación y apertura al diálogo entre los líderes políticos locales (municipales y demás actores locales, se debería en cierta medida al comportamiento poco cooperativo de los demás actores locales institucionales (véase el cuadro 10). Esta forma de comportamiento de los diferentes actores integrantes institucionales a nivel local respondería o estaría influida por aquella tradición política y cultura política locales. Donde cada uno busca su propio protagonismo político para la implementación de una determinada política de desarrollo local.Además, esta lógica de comportamiento de los demás actores institucionales es percibida de manera relativamente homogénea por nuestros entrevistados en los ámbitos locales estudiados.

Cuadro 9: Forma de coordinación de las autoridades locales con otros actores locales por regiones estudiadas (en porcentajes).

\begin{tabular}{|l|r|r|r|r|r|}
\hline \multicolumn{1}{|c|}{$\begin{array}{l}\text { Forma de coordinación entre } \\
\text { los actores locales }\end{array}$} & \multicolumn{3}{|c|}{ Región } & \multirow{2}{*}{ Total } \\
\cline { 2 - 5 } & \multicolumn{1}{|c|}{ Puno } & Ayacucho & Cajamarca & Lima-VES & \\
\hline $\begin{array}{l}\text { Siempre hay coordinación sobre } \\
\text { proyectos importantes }\end{array}$ & 16,7 & 10,0 & 40,0 & 25,0 & 22,9 \\
$\begin{array}{l}\text { Coordinan de vez en cuando sobre } \\
\text { proyectos importantes }\end{array}$ & 27,8 & 35,0 & 25,0 & 25,0 & 28,6 \\
$\begin{array}{l}\text { Coord. en palabra pero no se } \\
\text { plasma en la práctica }\end{array}$ & 22,2 & 35,0 & 25,0 & 41,7 & 30,0 \\
No coordinan nunca & 33,3 & 20,0 & 10,0 & 8,3 & 18,6 \\
Total & 100,0 & 100,0 & 100,0 & 100,0 & 100,0 \\
\hline
\end{tabular}

Fuente: Elaboración propia a partir de los resultados de las entrevistas realizadas en las cuatro regiones estudiadas, 2005 y 2006. 
Cuadro 10: Comportamiento de los demás actores locales institucionales por regiones estudiadas (en porcentajes).

\begin{tabular}{|l|r|r|r|r|r|}
\hline \multicolumn{1}{|c|}{ Comportamiento de las } & \multicolumn{4}{|c|}{ Región } & \multirow{2}{*}{ Total } \\
\cline { 2 - 5 } demás autoridades locales & \multicolumn{1}{|c|}{ Puno } & Ayacucho & Cajamarca & Lima-VES & \\
\hline De apertura y coordinación & 27,8 & 20,0 & 50,0 & 33,3 & 32,9 \\
Críticos constructivos & 0,0 & 0,0 & 10,0 & 0,0 & 2,9 \\
Críticos destructivos & 27,8 & 0,0 & 0,0 & 0,0 & 7,1 \\
Con poca voluntad de & 44,4 & 80,0 & 40,0 & 66,7 & 57,1 \\
cooperación & 100,0 & 100,0 & 100,0 & 100,0 & 100,0 \\
Total & & & & \\
\hline
\end{tabular}

Fuente: Elaboración propia a partir de los resultados de las entrevistas realizadas en las cuatro regiones estudiadas, 2005 y 2006.

\section{Estilos del liderazgo político local: aspiraciones en torno a un es- tilo del liderazgo político ideal}

De acuerdo con lo expuesto en las secciones anteriores, en los ámbitos locales estudiados se desarrollan, predominantemente, dos estilos de liderazgo político: el "autoritario-paternalista" y el "democrático-populista", puesto que cada una de las dimensiones consideradas para el análisis del proceso del liderazgo político se ha desarrollado de manera complementaria en el marco de las características de aquellos estilos del liderazgo, a saber: en cuanto al modelo de toma de decisiones, los alcaldes-líderes toman las decisiones políticas de acuerdo al modelo de la racionalidad incremental o al modelo incremental-reactivo y la agenda política se define de manera unilateral, $y$ en algunos casos de manera relativamente abierta.

En cuanto al rol y comportamiento político, los alcaldes-líderes actúan, en mayor medida, de forma reactiva en una perspectiva tendencia de corto plazo; su rol se concentra en la supervisión de las acciones municipales y en el mantenimiento o reproducción del statu quo, y en algunos casos, sobre esa base promueven políticas locales con otros actores, aunque dichas políticas son de carácter populista y generan dependencia de los actores localesdemás respecto de los actores entes gubernamentales y (o) privados.

Ahora bien, en relación a la forma de ejercicio del poder, los alcaldes-líderes basan sus acciones políticas en las jerarquías de autoridad y en el control del poder,y en algunos aspectos buscan consensos esporádicos. Finalmente, respecto a la construcción de redes de apoyo, los alcaldes-líderes basan su estrategia en las relaciones de autoridad formal y coercitiva, en las relaciones clientelares simétricas y asimétricas, y en las relaciones sociales basadas en el parentesco y la amistad.

Estos estilos del liderazgo político son los que se desarrollan de manera predominante en los ámbitos locales estudiados, los cuales son más marcados en Puno y Ayacucho, y en menor medida, en Cajamarca yVilla el Salvador. Sin embargo, en cada uno de los 
ámbitos, los alcaldes-líderes presentan algunas características de los estilos del liderazgo directivo-tecnocrático y democrático-visionario, aunque éstos no son los estilos característicos de la mayoría de los alcaldes-líderes.

Como respuesta a todo lo anterior, nuestros entrevistados han expresado sus aspiraciones en torno a un estilo del liderazgo político ideal para impulsar adecuadamente las políticas de desarrollo en sus ámbitos locales. Estas aspiraciones, de manera consensuada por regiones, se centran en la demanda de "un estilo del liderazgo político democrático-visionario" (véase los cuadros II y I2). ${ }^{9}$ Todo ello implica que el impulso del desarrollo local participativo requiere de modo imprescindible la promoción y el incentivo de un estilo del liderazgo político posmoderno, donde los líderes políticos demuestren su capacidad tomando en cuenta los siguientes aspectos:

- $\quad$ El proceso de toma de decisiones deberá basarse en algunos atributos de la planificación racional estratégica y la agenda de acciones políticas se definirá multilateralmente, es decir, de manera participada y concertada.

- El comportamiento político será proactivo con una orientación a largo plazo, cuyo rol político debe estar orientado a desarrollar las capacidades socioinstitucionales y promover nuevas políticas de transformación en el contexto local, con el fin de solucionar los problemas socioeconómicos locales.

- Las acciones políticas se fundamentarán en la búsqueda del consenso a través de la negociación y la deliberación participada.

- $\quad$ Las redes de apoyo político tendrán como base las relaciones formales de autoridad, en torno al logro de objetivos comunes y según sean estas utilitarias simétricas.

Cuadro I I: Estilo del liderazgo ideal para los ámbitos locales por regiones estudiadas (en porcentajes).

\begin{tabular}{|l|r|r|r|r|r|}
\hline \multirow{2}{*}{$\begin{array}{c}\text { Estilos de liderazgo ideal } \\
\text { a nivel local }\end{array}$} & \multicolumn{4}{|c|}{ Región } & \multirow{2}{*}{ Total } \\
\cline { 2 - 5 } & \multicolumn{1}{|c|}{ Puno } & Ayacucho & Cajamarca & Lima-VES & \\
\hline Liderazgo democrático-populista & 16,7 & 10,0 & 15,0 & 16,7 & 14,3 \\
Liderazgo autoritario-paternalista & 5,6 & 0,0 & 0,0 & 0,0 & 1,4 \\
Liderazgo democrático-visionario & 50,0 & 65,0 & 55,0 & 66,7 & 58,6 \\
Liderazgo directivo-tecnocrático & 27,8 & 25,0 & 30,0 & 16,6 & 25,7 \\
Total & 100,0 & 100,0 & 100,0 & 100,0 & 100,0 \\
\hline
\end{tabular}

Fuente: Elaboración propia a partir de los resultados de las entrevistas realizadas en las cuatro regiones estudiadas, 2005 y 2006.

9 Este estilo de liderazgo político se ha construido en respuesta a la dinámica y complejidad que presenta el objeto de estudio y unidad de análisis, tomando como referencia algunas aproximaciones teóricas en torno al liderazgo político, expuestas en la primera parte de este artículo. 
Cuadro 12: Estilo del liderazgo ideal para los ámbitos locales por tipo de actor entrevistado (en porcentajes).

\begin{tabular}{|l|r|r|r|r|}
\hline \multirow{2}{*}{ Estilos de liderazgo ideal } & \multicolumn{2}{|c|}{ Tipo de actor entrevistado } & \multirow{2}{*}{ Total } \\
\cline { 2 - 4 } \multicolumn{1}{|c|}{ a nivel local } & Municipal & \multicolumn{1}{c|}{ Estatal } & Soc. civil & \\
\hline Liderazgo democrático-populista & 15,0 & 15,0 & 13,3 & 14,3 \\
Liderazgo autoritario y paternalista & 0,0 & 0,0 & 3,3 & 1,4 \\
Liderazgo democrático participativo & 65,0 & 55,0 & 56,7 & 58,6 \\
Liderazgo directivo-tecnocrático & 20,0 & 30,0 & 26,6 & 25,7 \\
Total & 100,0 & 100,0 & 100,0 & 100,0 \\
\hline
\end{tabular}

Fuente: Elaboración propia a partir de los resultados de las entrevistas realizadas en las cuatro regiones estudiadas, 2005 y 2006.

\section{Conclusiones}

En la medida que se han implementado mecanismos de participación ciudadana generando una mayor proximidad y mejor coordinación de las autoridades con los ciudadanos en los ámbitos locales, la evaluación del comportamiento político de las autoridades locales por parte de la comunidad tiende a ser positiva, y viceversa. Además, la evaluación del comportamiento político de los alcaldes-líderes se plasma de manera complementaria a partir del desempeño de diversas actividades o roles de carácter político, ya sea en la búsqueda de apoyos y recursos, como jefe de la administración y negociador, y en algunos casos como impulsor de proyectos de desarrollo socioeconómico local.

Dado que la asignación de roles y funciones en los gobiernos locales en lo político, en lo administrativo y en lo técnico no es clara, la delegación de funciones y competencias municipales hacia los niveles inferiores están relacionadas con la ejecución de las decisiones tomadas en las instancias superiores de gobierno. Esto nos indica que el rol y el comportamiento político de las autoridades locales están condicionados por el sistema político nacional, la estructura organizativa municipal y la cultura política local, puesto que la asignación o redistribución de las funciones políticas, administrativas y técnicas al interior de los gobiernos locales están concentradas en mayor medida en el ápice estratégico, conformado por los políticos y técnicos. Aunque este proceso convencional de gestión de los gobiernos locales durante los últimos años ha sido permeabilizado por la emergencia de los nuevos mecanismos de participación ciudadana, haciendo que las decisiones del gobierno local tengan una mayor sensibilidad con el entorno social.

En la medida que el sistema político presidencialista, la estructura de organización vertical y la cultura política local caudillista generan una concentración del poder de toma de decisiones en el alcalde y su entorno político, entonces, la toma de decisiones en los ámbitos locales es de carácter imprevisto o no planificado y respon- 
de a un horizonte temporal de corto plazo, es decir, las decisiones se van tomando sobre la marcha en la construcción de la agenda política del líder. De modo que el estilo decisorio de los líderes políticos tiende a ser, en mayor medida, de carácter individualista-autoritario, cerrado y muy poco participativo, aunque hay un proceso formal de decisiones participadas que se viene desarrollando tímidamente con la implementación de los nuevos mecanismos de participación ciudadana en el país. Este modelo convencional de toma de decisiones implementado en los gobiernos locales ha hecho que la frecuencia de comunicación de las autoridades locales con los ciudadanos sea, en general, considerablemente baja, cuya agenda de acciones responde en menor medida a las demandas y necesidades sentidas de los ciudadanos.

De otra parte, los alcaldes-líderes, ejercen el poder en función a los rasgos autoritarios y caudillistas, propios de la época de las haciendas o del latifundismo, según los cuales la agenda de acciones municipales es definida unilateralmente. De esta manera, el modelo de ejercicio del poder por parte de aquellos líderes es cerrado, porque los diferentes sectores sociales e institucionales son excluidos del proceso de las políticas locales. Este modelo de ejercicio del poder por parte de los líderes políticos locales está ligado a la tradición y la cultura política locales, porque sus acciones están basadas en la estructura jerárquica de autoridad, donde el control y la posesión del poder da menos importancia al diálogo, la participación ciudadana y al establecimiento de las redes de relaciones entre la comunidad y la autoridad local.

A partir de lo anterior se pude concluir que el liderazgo en el proceso participativo tiene dos orientaciones: primero, es dónde y cuándo los alcaldes-líderes implementan mecanismos de participación ciudadana, únicamente, para proveer información a los ciudadanos en cuanto a la gestión económica municipal (rendición de cuentas), por lo general, anualmente, estos líderes ejercen el poder de acuerdo a los rasgos relativamente autoritarios y la coordinación de sus acciones políticas se basa en la autoridad del alcalde y prefieren hacer uso de los instrumentos de mando y control. En segundo lugar, es dónde y cuándo los alcaldes-líderes implementan mecanismos de participación ciudadana para el proceso de identificación de problemas y definición de políticas locales (proceso de toma de decisiones), estos líderes ejercen el poder de acuerdo a los rasgos cooperativos, cuya coordinación de acciones políticas se basa en el consenso y los instrumentos de negociación y la deliberación.

Asimismo, en la medida que las redes de relaciones políticas de los alcaldeslíderes están basadas mayoritariamente en el control del poder y mando, entonces el grado de coordinación y la apertura al diálogo entre las autoridades locales y demás actores inmersos en los ámbitos locales tiende a ser bajo, este hecho es más marcado en Ayacucho y Puno en comparación con los casos de Cajamarca y Villa el Salvador. La tendencia al bajo grado de coordinación y apertura al diálogo entre los líderes políticos locales (municipales) y demás actores locales se debería en cierta medida al comportamiento poco cooperativo de los demás actores institucionales a nivel local. Esta forma de comportamiento de los diferentes actores institucionales a nivel local respondería o estaría influida por aquella tradición política y cultura política locales. 
Donde cada actor institucional busca su propio protagonismo político para la implementación de una determinada política de desarrollo local.

Finalmente, en los ámbitos locales estudiados se dan, predominantemente, los estilos de liderazgo político autoritario-paternalista y democrático-populista, puesto que cada una de las dimensiones consideradas para el análisis del proceso del liderazgo político se han desarrollado de manera complementaria en el marco de las características de estos dos estilos del liderazgo. Como hemos sostenido anteriormente, el estilo convencional de hacer política por parte de los diferentes líderes está basado en los principios autoritarios, paternalistas y caudillistas, principios que formaron parte de la tradición y la historia política del país. En este sentido, las teorías del mesianismo y la dependencia, expresado en el modelo de gobierno con alcalde fuerte de Mouritzen y Svara, se plasman en la práctica política en los ámbitos locales de Perú. En este contexto, es que nuestros entrevistados han expresado sus aspiraciones en torno a un estilo del liderazgo ideal para impulsar adecuadamente las políticas de desarrollo en sus ámbitos locales. Estas aspiraciones, de manera consensuada por regiones, se centran en la demanda de un estilo del liderazgo político democrático-visionario.

\section{Bibliografía}

Alba, C.y Navarro, C. (2006). “Mayors and Local Administrators:A Puzzling Relationship”. En Back, H., Heinelt, H. y Magnier, A. (eds.), The European Mayor. Political Leaders in The Changing Context of Local Democracy.Alemania:VSVerlag Für Sozialwissenschaften, pp. 287-310.

Bass, B. M. (1990). Bass and Stodgill's Handbook of Leadership:Theory, Research and Managerial Applications, $3^{\mathrm{a}}$ edición. Nueva York:The Free Press.

Blanco, I. y Gomà, R. (2002). Gobiernos locales y redes participativas. Barcelona: Ariel Social.

Diez, A. (1999). "Organizaciones de base y gobiernos locales rurales. Mundos de vida, ciudadanía y clientelismo”. En Bardales, E. (ed.), Repensando la política en el Perú. Lima: Red para el Desarrollo de las Ciencias Sociales en el Perú, pp. 17-59.

Font, J. (2002). Local Participation in Spain: Beyond Associative Democracy. Barcelona: ICPS. Getemis, P. y Hlepas, N. (2006). “Aspects of Leadership Styles:An Interaction of Context and Personalities”. En Back, H., Heinelt, H. y Magnier, A. (eds.), The European Mayor. Political Leaders in The Changing Context of Local Democracy. Alemania:VS Verlag Für Sozialwissenschaften, Pp. I77-200.

Goldsmith, M. y Newton, K. (1997). “Gobierno local en el mundo moderno”. En Alba, C. y Vanaclocha, F. (eds.), El sistema político local: un nuevo escenario de gobierno. Madrid: UC3M-BOE.

Haus, M. y Sweeting, D. (2006). “Mayors, Citizens and Local Democracies”. En Back, H., Heinelt, H. y Magnier, A. (eds.). The European Mayor. Political Leaders in the Changing Context of Local Democracy.Alemania:VSVerlag Für Sozialwissenschaften, Pp. I5I-I76.

Heinelt, H. y Hlepas, N. (2006). “Typologies of Local Government Systems”. En Back, 
H., Heinelt, H. y Magnier, A. (eds.). The European Mayor. Political Leaders in the Changing Context of Local Democracy. Alemania:VSVerlag Für Sozialwissenschaften, Pp. 2 I-42.

Hernández, R., Fernández, C.y Baptista, P. (199I). Metodología de la investigación. México: McGRAW-HILL.

King, G., Keohane, R. O.y Verba, S. (2000). El diseño de la investigación social. La inferencia científica en los estudios cualitativos. Madrid:Alianza Editorial.

Mintzberg, H. y Brian, J. (1993). El proceso estratégico. Conceptos, contexto y caso. 2da. Edición. México: Prentice Hall.

Mouritzen, P. E. y Svara, J. H. (2002). Leadership at the Apex. Politicians and Administrators in Western Local Governments. Pittsburgh.

Natera, A. (200I). El liderazgo político en la sociedad democrática. Madrid: Centro de Estudios Políticos y Constitucionales.

Navarro, C.J. (2004). Sociedades políticas locales: democracia local y gobernanza multinivel. UAM, Madrid:Working papers on line, $\mathrm{n}^{\circ} 34$.

Panfichi, A. (2007). La participación ciudadana en el Perú. Disputas, confluencias y tensiones. Lima: Fondo Editorial de la PUCP.

Pascual, R. (1987). Liderazgo y participación: mitos y realidades. Bilbao: Universidad de Deusto.

Pateman, Carole (1970). Participation and Democratic Theory. Cambridge University Press.

Quispe, E. (2003). Condicionantes de la participación y articulación entre los actores en los espacios de concertación para el desarrollo local: experiencias de concertación en Moho y Carhuaz. Tesis de maestría no publicada. PUCP, Lima.

Quispe, E. (2006). “Pautas para la adecuada gestión de los gobiernos locales”. En Revista de Análisis THAKI, 3(4), pp. 5-9.

Quispe, E. (2007). “Liderazgo político para la planificación del desarrollo local participativo”. En Revista de Análisis THAKI, 4(5), pp. 4-8.

Stewart, J. (200I). "De la innovación democrática a la democracia deliberativa”. En Font, J. (coord.) Ciudadanos y decisiones públicas. Barcelona: Editorial Ariel, pp. 77-94

Stoker, G. (2000). Participation of Citizens in Local Public Life. Local and Regional Authorities in Europe, $n^{\circ} 72$. Germany: Council of Europe Publishing.

Vargas, C. E. (2003). Liderazgos en transición. Trayectorias de liderazgo político en el Perú. Ponencia presentada al taller latinoamericano "Sociedad civil, esfera pública y democratización en América Latina”. Xalapa, México.

Vilalta, M. (2004). "El ayuntamiento como prestador de servicios". En Liderazgo y representación política en los entes locales. Ponencia presentada al I Seminario pensando lo local en un nuevo siglo. Granada, España, 20 y 21 de febrero de 2003. UIM-Fundación Pi i Sunger-CEMCI. Granada. 